\title{
Synthesis: IWRM lessons for implementation
}

\author{
Aileen Anderson ${ }^{1 *}$, Eiman Karar $^{2}$ and Stefano Farolfi ${ }^{3}$ \\ ${ }^{1}$ Independent Researcher, London School of Economics and Political Science, Department of Management, LSE, \\ Houghton Street, WC2A $2 A E$, UK \\ ${ }^{2}$ Water Research Commission, Private Bag X03, Gezina 0031, South Africa \\ ${ }^{3}$ CIRAD UMR G-EAU and CEEPA, University of Pretoria, South Africa
}

\begin{abstract}
This paper provides a synthesis of the main issues discussed at a conference (International Conference on Integrated Water Resource Management (IWRM) entitled: Lessons from Implementation in Developing Countries which took place from 10 to 12 March 2008 in Cape Town, South Africa, at the Cape Town International Convention Centre) which was coordinated to share experiences and lessons learned on the implementation of IWRM in developing countries. This paper discusses six themes that emerged from the conference. These themes provide a perspective on the current status of IWRM and assist in formulating the agenda for further research and implementation approaches based on lessons learned. Firstly, although there is considerable history and international acceptance of IWRM, there is still ongoing debate on how IWRM is defined. However, aside from these debates there is general agreement on the principles underlying IWRM and the potential it holds for managing complex systems that cannot be adequately achieved through the single-sector management approach of the past. To overcome past management paradigms, new capacity building approaches are required. Secondly, implementation of IWRM requires a balance between policy and institutional support and community level projects that have small-scale tangible results for the poor. Thirdly, IWRM involves integration across many spheres, specifically the integration of groundwater management into long-term water resource planning. Fourthly, although there is general endorsement of the importance of public engagement in supporting IWRM approaches, effective public engagement requires considerable strategic planning to ensure that efforts are both applicable and relevant to those involved. Fifthly, the conference highlighted the importance of developing appropriate economic methods and instruments to address the economic trade-offs and decisions that are apparent in water management. Finally, appropriate data, information systems and indicators are required to adequately monitor progress with IWRM implementation.
\end{abstract}

Keywords: integrated water resource management, implementation, managing complex systems, poverty alleviation

\section{Introduction}

To celebrate the 10-year anniversary of implementing the South African Water Act, a 3-day conference was held to share experiences and lessons learned on the implementation of IWRM in developing countries. The workshop was attended by 200 international delegates from across the water sector. The conference themes included water for growth and development, IWRM and environment, IWRM and the economy, IWRM and society. The conference provided an opportunity for extensive debate and analysis of IWRM approaches and implementation lessons. Although the collection of papers presented in this edition covers a range of the issues presented and discussed at the conference, they do not include the full dearth of issues. This paper provides a summary of the main issues outlined in the 10 papers as well as touching on additional themes and findings that were discussed during the conference; provides a perspective on the current status of IWRM; and assists in formulating new agendas and approaches for further research and implementation based on lessons learned.

\footnotetext{
* To whom all correspondence should be addressed. e-mail: a.j.anderson@lse.ac.uk
}

\section{Defining IWRM}

The concept of IWRM is widely endorsed over the alternative and it has emerged as the dominant paradigm for water management in rich and poor countries. The IWRM approach has been endorsed by many international agencies as a holistic approach to water resource management and is being increasingly accepted and integrated in the planning and decision-making processes of water managers and policy-makers. Although some argue that IWRM has been practised in different forms for many decades, its origins are usually traced to the 1992 Dublin Principles. The concept was also promoted by several international organisations prior to Dublin, at forums such as the UN Water Conference in Mar del Plata in 1977 (Biswas, 2004). Regardless of its exact origins, IWRM emerged in response to the much-criticised, sector-by-sector approach to water management. The UN World Water Development Report (2006) states that 'IWRM represents a holistic, ecosystem-based approach which, at both strategic and local levels, is the best management approach to address growing water management challenges and is seen as the best approach for meeting the Millennium Development Goals' (UNESCO-WWP 2006, p. 526).

Aside from its considerable history and international acceptance, the conference highlighted the ongoing debate on the difficulties in developing a clear and common definition of IWRM. Biswas (2008) argues that even after more than half a century of existence, there is still no acceptable operational definition as to what IWRM is and which issues should be integrated. 
Several authors have provided valuable comparisons and analyses of the range of IWRM definitions (Cardwell et al., 2006; Davis, 2007; Hooper, 2006). Davis (2007) provides a comprehensive review of IWRM definitions and presents IWRM as an approach which results in better water use, supporting economic and social objectives, while maintaining environmental ecosystems. This is achieved through integrated, collaborative, and multiple objectives and strategic and operational planning and implementation processes that involve stakeholders, rather than using fragmented, single focuses planning and implementation with limited participation. Molle (2008) provides a valuable analysis of IWRM as a 'nirvana concept' which embodies an ideal image of what the world should tend to and which represents a "vision of a "horizon" that individuals and societies should strive to reach. Although, just as with nirvana, the likelihood that we may reach them is admittedly low, the mere possibility of achieving them and the sense of "progress" attached to any shift in their direction suffice to make them an attractive and useful focal point' (p. 132).

\section{IWRM and the management of complex systems}

Dialogues on how to define IWRM have value as they assist in ensuring that IWRM does not simply become popular because its amorphous nature makes it easier for people to continue to do whatever they were doing before and to simply rename it to follow the latest paradigm (Biswas, 2004). Such an eventuality will weaken the value that IWRM thinking and approaches offer to the management of complex water resources. The conference provided an opportunity to move beyond definitions and consider how IWRM can be implemented to achieve better results than the the single-sector approaches of the past.

Pollard and $\mathrm{Du}$ Toit (2008) provide a valuable reflection of why IWRM is most suited for managing complex systems as it requires an understanding of linkages, multiple drivers and unpredictable outcomes. An iterative, 'learning-by-doing' approach that is reflexive in nature and builds learning into the next management cycle is seen as essential. They consider past single sector management approaches which were unable to deal adequately with the challenges of complex and rapidly changing systems. They argue that South Africa's National Water Act and associated policy documents, such as the National Water Resources Strategy, are examples of policy documents that reflect this integrated thinking. The paper focuses on the newly developed catchment management strategy (CMS) guidelines which present a framework for an integrated, systems approach to IWRM. Pollard and Du Toit (2008) provide an overview of the CMS guidelines and the strategic path it offers in achieving equity and sustainability in water resource management Although specific to South Africa, the CMS's present an example that could be adapted and applied elsewhere for how strategic plans - if collaboratively, judiciously and thoughtfully developed - can be designed to support IWRM implementation.

\section{Renewed effort on implementation}

A key emphasis of the conference was that although there are still different definitions of IWRM, there is a common understanding of its fundamental principles and approaches. The complex combination of government agencies and processes that need to be coordinated to ensure IWRM is successful means that implementation is significantly more challenging than in traditional single-sector responses. The result should be a more sustainable and effective management response but more needs to be learnt and shared on how to achieve this integrated 'nirvana'. The conference highlighted the need for a concerted shift away from the debates on definitions and towards identifying implementation mechanisms and approaches.

Colvin et al. (2008) outline many of the significant water resource management implementation challenges that face IWRM. Much of South African water policy is considered to be some of the most progressive policy thinking in the world and is based on an IWRM approach. However, as is often the case, progressive policy is not always supported by progressive implementation. They discuss many of the significant delays in numerous areas of implementation, including the establishment of water management institutions. They argue that effective capacity building is required to support implementation. Recent approaches by DWAF have not been successful and are characterised by one-way, expert-driven approaches. They recommend a more progressive approach that is based on an iterative, learn-by-doing approach to capacity building. The capacitybuilding approach, called Watercourse, was launched based on IWRM implementation experiences in the UK. The Watercourse approach sees IWRM not as a management strategy, but as a set of principles and practices which facilitate learning and adaptive approaches. The results demonstrate early successes in enabling different stakeholder groups to engage in dialogue around issues of shared interest based on a common resource. The authors contend that in South Africa, the focus on institutions and structures has drawn attention away from the much harder, and perhaps more important task of building capacity for implementation. Moving away from the traditional top-down approaches, the paper offers some useful mechanisms to achieve interactive learning, opening up spaces for 'making sense' of IWRM policies and offering a means of creating change in complex situations against a background of highly uneven development.

\section{Balancing IWRM implementation approaches}

The conference highlighted the importance of balancing the establishment of enabling environments, which includes legislation, policies and institutional structures, with smaller-scale projects that have more tangible, immediate benefits for the poor. Over-emphasis on the policy and legislation component leaves little benefit to those on the ground and does little to effect real change or promote poverty reduction. However, ignoring the enabling environment may hamper longer-term formalisation of IWRM approaches which could, in a particular context, limit the sustainability of IWRM.

Leendertse et al. (2008) discuss these approaches from an ecosystem perspective. The authors pose two central questions to the current IWRM implementation discourse, 'What is an acceptable lag time between initiating an IWRM approach and obtaining tangible impacts and benefits?' and 'What measures can be put in place to shorten this lag time?' If the process continues for too long with no apparent progress, people will become disillusioned and will revert to the management methods they used previously. The paper argues that where the process is top-down, with little stakeholder engagement, institutional and legal changes will have little effect on the way water is used and managed, with few tangible improvements in water quality and ecosystem protection.

They further argue that the environment is often least considered when water management policies and plans are being developed and is often even more neglected when it comes to implementation. Of all the sectors, the environment has the most 
to gain from the implementation of IWRM principles. Based on case analyses from Malaysia and South Africa, several different water management instruments are discussed that address environmental concerns in managing ecosystems. In Malaysia, the focus is on basin management and implementable action, whereas in South Africa the emphasis has been on setting up regulatory and organisational structures first before implementing integrated management. A series of additional case studies are briefly examined to assess how the environment has benefited from different water policies. The case studies cover a spectrum of approaches from bottom-up ones that show positive and more immediate results and benefits, to more top-down approaches dealing with many organisations and people to whom the process may not be central to their interests and where strong institutional support is required to ensure success.

Although not included in this edition, other presentations at the conference emphasised the importance of linking IWRM implementation to tangible poverty-alleviation projects. Several case studies where presented which reflected this grassroots approach, such as in the Olifants/Doorn WMA in South Africa, and in the implementation of the National IWRM framework in the Philippines. They showed that IWRM is most effective when initiatives actively empower disadvantaged groups through their involvement in projects that serve to improve the livelihoods and well-being of communities. Through practical projects, communities developed an understanding of a broad spectrum of water management issues and are thus able to be more effectively engaged in water issues within local water management institutions. Community members need to first understand how water benefits them before they become involved in decisions regarding its management. Many of these grassroots projects are also able to overcome the challenges of integrating government agencies because the tangible nature of projects makes it easier to obtain government agency buy-in. This creates ongoing coordination and relationships between key actors, which can facilitate future policy level integration. Several case studies at the conference highlighted the importance of supporting tangible projects that can be implemented even when the enabling environment of policy and legislation is not consistently aligned with all IWRM principles.

\section{Integration across the hydrological cycle}

IWRM discourse often focuses on the integration of the three E's: economic, environment and equity. However, this only considers one of the many integration dimensions of the approach. IWRM also includes integration of several elements such as land and water issues, freshwater and coastal zones, green vs. blue water (this is defined as the water consumed in the direct production of biomass as opposed to that flowing in rivers and aquifers) water quantity and quality, differing upstream and downstream interests and interactions between surface-water and groundwater resources (GWP, 2000). Braune and Xu (2008) contend that groundwater, largely because of its hidden and generally poorly understood nature, is seldom properly incorporated into IWRM and national development frameworks. While there are problems of widespread pollution of groundwater as well as more localised, over-abstraction, the much bigger issue is a general under-valuation and concomitant under-utilisation of groundwater resources. In Africa, there is now a growing perception that local groundwater resources will have to play an increasingly strategic role, in particular, for the most vulnerable and most neglected rural communities.
To assess the Southern African status of groundwater resource management, the authors undertook a scoping level study. The approach involved assessing the groundwater resource management status in SADC countries based on available documents and scientific literature from the area and comparing them against generally accepted 'best practice' from international groundwater management literature. The outcomes show that, while SADC is leading the other regional economic communities in Africa, implementation performance in individual countries is rated as 'below expectation.' The reasons for this include a general lack of appropriate planning, financing and systematic resource development approaches to support local participation and investment in numerous small, local schemes. In addition, groundwater information, including monitoring and assessment, and the capacity for it, is generally inadequate in most countries. The authors argue that there is a need to move away from traditional supply-driven groundwater development towards seeing groundwater as part of an integrated and holistic plan for water management at all planning levels. This should lead to a strategic management framework, resulting in the formulation and implementation of national development and IWRM policies and programmes.

\section{Public participation in IWRM}

Although there is general endorsement of the importance of public engagement in supporting the successful implementation of IWRM approaches, effective public engagement requires considerable strategic planning to ensure that efforts are both applicable and relevant to those involved. Based on South African experience in the complexities of public engagement in establishing catchment management agencies in South Africa, Du Toit and Pollard (2008) outline a framework for public engagement in the IWRM process. Drawing from capacity development programmes in the Kat and Sand catchments, a checklist of issues and consequences to consider in structuring public participation in the IWRM process is presented. Although drawn from South African experience, many of the principles can be universally applied. The paper goes on to specifically address the process of developing CMSs in South Africa. The paper outlines the importance of determining the requisite level of public engagement that is required to reflect each task within the IWRM process. The levels of participation vary according to the specific stages of a water management task. For example, it may not be necessary to engage the public in highly technical decision-making processes which rely on specialised information. The objective is to ensure that the correct stakeholders are meaningfully and appropriately engaged in the CMS development process. The paper presents a clear and practical guide to engaging the public in the various tasks associated with IWRM in South Africa.

\section{Economic instruments}

'Economy and IWRM' was one of the themes of the conference and the outcomes of the workgroup emphasised the importance of developing appropriate economic methods and instruments to address many of the trade-offs that are apparent in water management. The conference highlighted the need for capacity building on the economic aspects of water management processes and for effective and carefully considered and informed policy-making. Kanyoka et al. (2008) provide an example of how economic analysis can support better decision making to achieve IWRM. The paper outlines how investments in water 
services should be based on a thorough understanding of effective consumers' demand for multiple use (both domestic and productive) water services. Comprehensive studies looking at multiple use water services are not common in South African rural areas, where most of the economic analyses focus on either domestic or irrigation water demand. The study fills this gap by assessing the household demand for multiple use water services in the Sekororo-Letsoalo area in the Limpopo Province. Results showed that households in rural areas are willing to pay for water service delivery improvements. Due to the current poor level of water services in the study area, users are primarily concerned with basic domestic uses and, consequently, demand for productive uses is low. An interest in multiple uses was only observed in households that already had enough water to satisfy basic domestic needs. Very poor conditions in terms of water availability not only drastically reduce the current livelihood of rural households, but also their ambitions and willingness to improve their economic status.

The authors go on to question block-tariffs as a recommended approach to cost recovery. A constant price per cubic meter associated with a subsidy, specifically targeted at poorer households is more suitable than block-tariffs. Pricing water on the basis of consumption implies metering water use, which is more costly than non-metered systems. Technical solutions, which control the quantity of water delivered at low management cost, such as pre-paid card systems used in electricity provision, may be better suited to low-income households. The authors elucidate the importance of carefully studying the level and structure of tariffs as well as the technological options used to obtain cost-recovery of water provision in poor rural communities.

\section{Information management and monitoring progress}

Throughout the conference, the importance of monitoring progress in IWRM was highlighted as an area requiring specific attention. The following papers touch on this aspect and outline the need for further analysis of appropriate approaches to manage, integrate and present data and information within a crossdisciplinary and multi-sectoral IWRM environment.

Complexity among numerous data formats, models and strategies in Thailand presented difficulties in hydrological planning and decision-making. To overcome these challenges, Thailand introduced an interactive data assimilation system, called the Thailand Hydroinformatic System (THS). Vathananukij and Malaikrisanachalee (2008) summarise the approach and the outcome of implementing THS. THS is a web-based GIS application that was designed and developed, based on open-source technology to publish hydro-meteorological data through the Internet. The outcome scenarios of the system have proved to be important decision-support tools. Precipitation and discharge data from 1995 are used in the system. In addition, essential data such as administrative boundaries, population, surface water resources, faults, and geology data are included to increase the potential uses of the system. The THS system has become increasingly essential to integrate information, and to transfer knowledge and technology. The virtual mechanisms have assisted in supporting public participation and in attaining and utilising information. The authors argue that similar developments in other countries could aid governments in understanding their water environment and thereby supporting better management decisions.
Anderson et al. (2008) further discuss the importance and challenges of information gathering to support IWRM. The authors emphasise the importance of developing effective means of assessing how IWRM actions meet the outcomes of efficiently managed, equitably allocated and environmentally sustainable water resource systems. Appropriate indicators, supported by well-managed information monitoring systems should be an integral component of all IWRM initiatives. In order to achieve this, IWRM faces the challenge of supporting and advancing the traditional hydrological monitoring requirements, while at the same time placing greater emphasis on a more holistic, crossdisciplinary approach to the integrated and complex dimensions of the hydrological cycle in particular. The paper outlines an integrated monitoring framework for measuring impacts of the South African water allocation reform process. The framework presents an innovative, GIS-based approach to integrated monitoring of water management interventions by combining economic, social and environmental data. As with all monitoring frameworks, success relies on an ability to integrate data and thinking across professional disciplines. This requires additional resources and involves a high degree of cooperation between different government agencies and spheres of government.

\section{Conclusion}

On the basis of its ability to address the integrated nature of managing complex water resource systems, few can argue against the value of an IWRM approach. Implementation of IWRM approaches should result in better water sharing between users, supporting economic and social objectives, while maintaining environmental ecosystems. Many cases, particularly those discussed from Africa, illustrate that IWRM is effective in achieving these outcomes. However, the conference clearly emphasised that more needs to be done to speed up implementation so that benefits and successes can be more easily identified.

A GWP survey in 2006 showed that two thirds of countries are at some stage of introducing IWRM as guiding principle for water management; however, much of this is related to establishing an enabling environment (including policy reform and institutional restructures) (GWP, 2006). Progress in widespread implementation is harder to gauge and will likely show fewer success stories. More effort is now required to demonstrate and monitor how implementation of IWRM is improving water management, specifically in relation to how the poor are benefiting. The United Nations World Water Development Report aptly argues that 'more analysis of the practical means of moving from a fragmented, sector-by sector approach to IWRM needs to be carried out for lower income countries, and these experiences need to be shared widely' (UNESCOWWP, 2006, p 527). The conference emphasised that we cannot use imperfect legislation and institutional structures as an excuse for slow implementation. IWRM provides a promising approach but it also represents an unattainable ideal, or as Molle (2008) argues a 'nirvana concept'. Perfect integration between all sectors, across the hydrological cycle and between all users is unlikely. One cannot wait to achieve this integration before tangible benefits are achieved on the ground. Benefits must include increased access to water services, socio-economic empowerment, protection of ecosystems, improvement in water quality and overall poverty reduction. Unless we can effectively show that IWRM approaches assist in achieving some of these benefits, the concept of IWRM will lose much of its promise in providing a more holistic and sustainable approach to managing scarce water resources. 


\section{References}

ANDERSON AJ and MAHLANGU MS, CULLIS J and SWARTZ S (2008) Integrated monitoring of water allocation reform. Water SA 34 (6) 731-737.

BISWAS AK (2004) Integrated water resources management: A reassessment. A water forum contribution. Water Int. 29 (2) 248-256.

BISWAS AK (2008) Integrated water resources management: Is it working? Int. J. Water Resour. 24 (1) 5-22.

BRAUNE E and YONGXIN XU (2008) Groundwater management issues in Southern Africa - An IWRM perspective. Water SA 34 (6) 699-706

CARDWELL HE, COLE RA, CARTWRIGHT LA and MARTIN LA (2006) Integrated Water Resource Management: Definition and conceptual musings. J. Contemp. Water Res. Educ. 135 8-18.

COLVIN J, BALLIM F, CHIMBUYA S, EVERARD M, GOSS J, KLARENBERG G, NDLOVU S, NCALA D and WESTON D (2008) Building capacity for co-operative governance as a basis for integrated water resources managing in the Inkomati and Mvoti catchments, South Africa. Water SA 34 (6) 681-690.

DAVIS MD (2007) Integrated water resource management and water sharing. J. Water Resour. Plann. Manage. September/October 2007. 427-444.

DU TOIT D and POLLARD S (2008) Updating public participation in IWRM: a proposal for a focused and structured engagement with catchment management strategies. Water SA 34 (6) 707-714.

GWP (Global Water Partnership) (2000) Integrated Water Resource Management. Global Water Partnership, Technical Advisory Committee Background Paper No. 4. Stockholm. www.gwpforum.org/ gwp/library/TACNO4.pdf.
GWP (2006) Setting the Stage for Change: Second Informal Survey by the GWP Network Giving the Status of the 2005 WSSD Target on National Integrated Water Resources Management and Water Efficiency Plans. Global Water Partnership, February 2006.

HOOPER B (2006) Integrated Water Resource Management: Governance, best practice, and research challenges. J. Contemp. Water Res. Educ. 135 1-7.

KANYOKA P, FAROLFI S and MORARDET S (2008) Households' preferences and willingness to pay for multiple use water services in rural areas of South Africa: An analysis based on choice modelling. Water SA 34 (6) 715-724.

LEENDERTSE K, MITCHELL SAM and HARLIN J (2008) IWRM and the environment: A view on their interaction and examples where IWRM led to better environmental management in developing countries. Water SA 34 (6) 691-698.

MOLLE F (2008) Nirvana concepts, narratives and policy models: Insight from the water sector. Water Alternatives 1 (1) 131-156. www.water-alternatives.org

POLLARD S and DU TOIT D (2008) Integrated water resource management in complex systems: How the catchment management strategies seek to achieve sustainability and equity in water resources in South Africa. Water SA 34 (6) 671-680.

UNESCO-WWP (2006) Water a shared responsibility: The United Nations World Water Development Report 2. United National Educational, Scientific and Cultural Organisation and Cultural Organisation, Paris, France.

VATHANANUKIJ $\mathrm{H}$ and MALAIKRISANACHALEE S (2008) Hydroinformatic system (implementation in Thailand). Water SA 34 (6) $725-730$. 